\title{
Women with Abnormal Endometrial Pathology: Experienced at a Tertiary Care Hospital in Bangladesh
}

\author{
Showkat $\mathrm{MS}^{1}$, Khondker $\mathrm{L}^{2}$, Nobi $\mathrm{S}^{3}$, Bhowmik B ${ }^{4}$
}

\begin{abstract}
Background: Transvaginal sonography is superior to transabdominal sonography in most cases of pelvic pathology. Objective: This study was undertaken to see the clinicalpathological characteristics of endometrial hyperplasia. Methodology: This cross sectional study was carried out from January 2007 to December 2008 for a period of two years. All suspected cases of endometrial hyperplasia were included for this study. Transvaginal sonography (TVS) performed and confirmation was done by histopathological examination. Result: A total number of 40 cases were enrolled for this study. The most common diagnosed endometrial pathology was endometrial hyperplasia which was $42.5 \%$ cases. Endometrial polyp was diagnosed in $32.5 \%$ cases. Endometrial carcinoma was in $7.5 \%$ patients and submucosal fibroid was in $10.0 \%$. Conclusion: Endometrial hyperplasia is the most common disease among the women presented with endometrial pathology. [J Shaheed Suhrawardy Med Coll, 2013;5(1):11-13]
\end{abstract}

Key words: Endometrial hyperplasia, histopathology of endometrial hyperplasia,endometrial pathology

Received: October 2012; Revised: March 2013; Accepted: May 2013

\begin{abstract}
Introduction
Abnormal uterine bleeding (AUB) is a common clinical manifestation of endometrial pathology for gynecologic visits $^{1}$. Up to $33^{\circ} \%$ of women referred to gynecological out patient clinics have AUB and this proportion rises to $69^{\circ} \%$ in a peri or postmenopausal group ${ }^{2}$. Endometrial pathology associated with AUB often cause thickening of endometrium which might be diffuse or focal. Endometrial hyperplasia is related to an abnormally high, prolonged level of estrogenic stimulation with diminution or absence of progestational activity. Endometrial hyperplasia $(\mathrm{EH})$ is considered to be a frequent cause of abnormal uterine bleeding ${ }^{3}$. Thus, hyperplasia occurs most commonly around menopause or in associated with persistent anovulation in younger women. Most importantly the differential diagnosis includes endometrial carcinoma, endometrial polyp and hydatidiform mole.The purpose of the present study was to see the disease profiles among the women presented with abnormal endometrial pathology.
\end{abstract}

\section{Methodology}

This cross sectional study was performad among patients who were clinically suspected having thickened endometrium during duration of 2 years to confirm the clinical diagnosis. Clinically suspected patients admitted in Department of Obstetrics \& Gynaecology suffering from endometrial pathology were enrolled in this study. The study was carried out in the Department of Radiology and Imaging at BSMMU with collaboration at the Department of Obst \& Gynecology, Department of Pathology and Histopathology of the same institute. The study was carried out January 2007 to November 2008 for a period of two years. All the information were collected in a pre-designed structured data collection sheet. Sampling method was purposive type of non-probability sampling. Inclusion criteria of selection of patients were pre, peri and post menopausal women with abnormal uterine bleeding for more than 6 months who were clinically suspected to have endometrial pathology and patients with abnormally thickened endometrium $(>15 \mathrm{~mm}$ in premenopausal women and $>5 \mathrm{~mm}$ in postmenopausal women) detected on transabdominal ultrasonography or transvaginal sonography. Exclusion criterias were patients having AUB due to causes other than endometrial pathology and patients who were unfit or unwilling to do TVS. Prior to

1. Dr Mst Syeeda Showkat, Assistant Professor, Department of Radiology and Imaging, Bangabandhu Sheikh Mujib Medical University (BSMMU), Dhaka

2. Dr. Lubna Khondker, Assistant Professor, Department of Dermatology and Venereology, Bangabandhu Sheikh Mujib Medical University (BSMMU), Dhaka

3. Dr Shahryar Nabi, Assistant Professor, Department of Radiology \& Imaging, Dhaka Medical College Hospital, Dhaka

4. Dr Bishwajit Bhowmik, Assistant Professor, Department of Radiology and Imaging, Bangabandhu Sheikh Mujib Medical University (BSMMU), Dhaka

\section{Correspondence}

Dr. Mst. Syeeda Showkat, Assistant Professor, Department of Radiology \& Imaging, Bangabandhu Sheikh Mujib Medical University (BSMMU), Shagbag, Dhaka, Bangladesh; Cell no.: +8801711314306; E-mail: drjany2008@yahoo.co.uk

Conflict of interest: No declared

Financial Support: None

Contributions by authors: All authors contributed from preparation of protocol to write up of the article. 
the commencement of this study, the research protocol was approved by the institutional review board (IRB). Specimen was obtained by endometrial curettage and /or hysterectomy specimen. Written consent was taken from all the patients after informing the necessary information regarding the research study. Then data were collected in a pre-designed structured data collection sheets. Data were collected from primary source starting from the clinical history and physical examination. The patients were followed up to histopathological diagnosis of endometrial curettage and/ or hysterectomy specimen. Further statistical analyses of the results were done by computer software device as statistical packages for social scientist (SPSS). The results were presented in tables, figures \& diagrams.

\section{Results}

A total of 40 consecutive cases were selected who were attended in the department of Radiology and Imaging at BSMMU with clinically diagnosed endometrial pathology. Histopathological examination was done from respective pathology department. It was the peri-menopausal women (40-50 years) who were suffering from the majority of the cases of endometrial abnormality among which endometrial hyperplasia was the commonest (figure I).

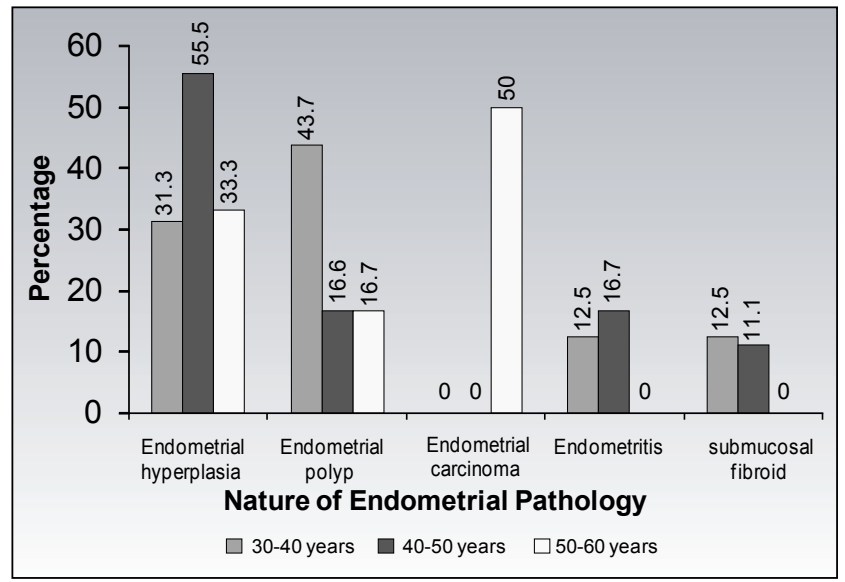

Fig. I: showing endometrial pathology according to age group

Among 40 patients the most common diagnosis was endometrial hyperplasia which included $18(45.0 \%)$ cases. The results are shown in figure 2. In this study the most common diagnosed endometrial pathology was endometrial hyperplasia which was $17(42.5 \%)$ patients cases. Endometrial polyp was diagnosed in $13(32.5 \%)$ patients. Endometrial carcinoma was in $3(7.5 \%)$ patients and Submucosal fibroid was in $4(10.0 \%)$ patients (Table-1).

Table 1: Histopathological Diagnosis of Different Endometrial Pathology

\begin{tabular}{lcc}
\hline $\begin{array}{l}\text { Endometrial } \\
\text { Abnormalities }\end{array}$ & Frequency & Percentage \\
\hline Endometrial hyperplasia & 17 & 42.5 \\
Endometrial polyp & 13 & 32.5 \\
Endometrial carcinoma & 3 & 7.5 \\
Submucosal fibroid & 4 & 10.0 \\
Total & $\mathbf{4 0}$ & $\mathbf{1 0 0 . 0}$ \\
\hline
\end{tabular}

\section{Discussion}

In this present study endometrial hyperplasia was diagnosed in $45.0 \%$ cases. Most of this appeared as diffuse and homogenous thickening of echogenic endometrium on Transvaginal Ultrasonography (TVS). El-Mowafi et $\mathrm{al}^{7}$ observed in their histopathological diagnosis that out of 42 cases normal postmenopausal atrophic endometrium was seen in $19(45.2 \%)$ cases which is similar to the present study and chronic endocervicitis was diagnosed in 5 of them. An endometrial pathology was found in $23(54.8 \%)$ patients, endometrial hyperplasia was diagnosed in $8(19 \%)$ cases, a polyp was found in $11(26.2 \%)$ cases, endometritis was found in $2(4.8 \%)$ cases and endometrial carcinoma was the histopathological report of $2(4.8 \%)$ cases. Endometrial echoes were visualized and measured by TVS in all cases. An abnormal endometrial texture was found in 17 of the 23 cases with endometrial pathology. Hyperplasia was diagnosed in 7 of the 8 cases, while the other case was diagnosed as normal atrophic endometrium. A polyp was diagnosed in 9 cases of the 11, while the other 2 cases were diagnosed as normal atrophic endometrium.

Maia et $\mathrm{al}^{11}$ found that endometrial hyperplasia was in 10 patients, all of them had abnormal uterine bleeding. The results of above authors are comparable with the present study. According to histopathological diagnosis of different endometrial pathology in this study it was observed that the most common diagnosed endometrial pathology was endometrial hyperplasia $42.5 \%$ which was. Endometrial polyp was diagnosed in $12.5 \%$ cases, endometrial carcinoma in $7.5 \%$ cases and submucosal fibroid was in $10.0 \%$ cases. Mathew et $\mathrm{al}^{12}$ found in their study that endometrial hyperplasia was $18.2 \%$, endometrial polyp was diagnosed in $39.1 \%$ cases and endometrial carcinoma in $0.9 \%$ cases in histopathological diagnosis. Wilailak et $\mathrm{al}^{13}$ found in their study that endometrial hyperplasia was $17.3 \%$ and endometrial polyp was diagnosed in $4.9 \%$ cases in histopathological diagnosis. Tsikouras et $\mathrm{al}^{14}$ observed on 123 postmenopausal women with suspicious endometrium $>5 \mathrm{~mm}$, endometrial polyps was $7.13 \%$, one cervical polyp with extension in the cavity $0.8 \%$, endometrial atrophies $73.1 \%$, atrophic endometritis $8.13 \%$, hyperplasia $1.62 \%$ and hyperplasia with atypia was $0.8 \%$.

\section{Conclusion}

The study finding permit to conclude that endometrial hyperplasia is the most common disease among the women presented with abnormal endometrial pathology followed by endometrial polyp and endometrial carcinoma.

\section{References}

1. Karampl E, Bourne T, Hurlen Solbakken H, Istre O. Transvaginal Ultrasonography, Sonohysterography and Operative Hysteroscopy for the Evaluation of Abnormal Uterine bleeding. Acta Obstet Gynaecol Scand 2001; 80 (7): 616 - 22

2. Mencaglia L, Perino A, Hamou J. Hysteroscopy in perimenopausal and post menopausal women with abnormal uterine bleeding. J Reprod Med 2007; 32: 577-582 
3. Loverro G, Bettocchi S, Pansini N, Porreca MR, Selvaggi L. Hyperplastic human endometrium. J Am Assoc Gynaecol Laparosc 2006; 3(4): 27

4. Qureshi IA, Ullah H, Akram MH, Ashfaq S, Nayyar S. Transvaginal versus transabdominal sonography in the evaluation of pelvic pathology. J Coll Physicians Surg Pak 2004; 14(7): 390-3

5. Crofton M. Gynecological Imaging. Sutton D (editor). Text book of Radiology and Imaging. 7th edition, London: Churchill Livingstone; 2003.1069-1105

6. Cacciatore B, Ramsoy T, Lehtoirta P, Ylostalo P. Transvaginal sonography and hysteroscopy in postmenopausal bleeding. Acta Obstet Gynecol Scand 2004;73: 413 - 16

7. El-Mowafi D, Farid A, El-Badawi A. Transvaginal Sonography and Hysteroscopy Versus Histopathology in Postmenopausal Bleeding. Obstetrics and Gynecology, Radiology and Pathology Departments, Benha Faculty of Medicine. Eygpt 2005; gfmer.ch/ International_ activities_En/.../Transvaginal_sonography.htm 4/9/2008

8. Goldstein S. Use of ultrasonohysterography for diagnosis of perimenopausal patients with unexplained uterine bleeding. Am J Obstet Gynecol 2004; 170: $565-70$

9. Bakos O, Heimer G. Transvaginal Ultrasonographic Evaluation of the Endometrium Related to the Histological Findings in Pre- and imenopausal Women. Gynecol Obstetric Investigation 2004; 45: 199-204

10. Andrews HS. Uterine pathology. Deubury K, Meire H, Cosgrove D (editors). Ultrasound in Obstetrics and Gynecology.2nd ed, Churchill Livingstone; 2003. 29-33
11. Maia H, Barbosa IC, Farias JP, Ladipo OA, Coutinho EM. Evaluation of the endometrial cavity during menopause. Intern Gynecol Obstet 2006; 52: 61-66

12. Mathew M, Gupta R, Krolikowski A. Role of transvaginal ultrasonograpy and diagnostic hysteroscopy in the evaluation of patients with abnormal uterine bleeding. Intern Gynecology and Obstet 2000; 71: 251-253 13. Wilailak S, Jirapinyo M, Theppisai U. Transvaginal Doppler sonography: is there a role for this modality in the evaluation of women with postmenopausal bleeding?, European Menopause 2005: 50: 111-16

14. Tsikouras P, Galazios G, Liberis V, Bouzaki A, Grapsas X, Maroulis G. TV sonographic assessment in postmenopausal asymptomatic women. Eur J Gynaecol Oncol 2007; 28(6): 473-6

15. Khatun A, Ahsan S, Mohiuddin AS, Sadeque ASQ, Akhter S, Hassain I, Azad SL,et at. Role of Transvaginal sonography in the evaluation of abnormal uterine bleeding with histopathological correlation. Bangladesh Radiology Imaging 2003; 11(1): 14-17

16. Tabbakh EL, Slanka P. Transvaginal Ultrasonography, Sonohysterography, Hysterosalpingography and Operative Hysteroscopy In: Predicting Endometrial Hyperplasia, www.obgyn.net, 27/10/2008

17. Grigoriou O, Kalovidouros A, Papadias C, Antoniou G, Antonaki V, Giannikos L. Transvaginal sonography of the endometrium in women with postmenopausal bleeding. Climacteric Postmenopause 1996; 23: 9-14. 